Baker, Ltd., Dagenham, Essex). This number is a well-printed, well-illustrated, folio-sized booklet of twelve pages. The promoters intend to furnish information on apparatus, reagents and techniques from the work in their own laboratories, and on matters of interest to chemists generally. There is also a hint of forthcoming articles of wide cultural appeal by outside contributors. The editors have certainly in this first number set themselves a good model and produced a well-balanced journal. The articles, all by specialists, are entitled: petroleum ; a gas-scrubbing tower; potassium borohydride; and in a secondary modern school. To complete the contents, there are four abstracts, illustrated and in smaller type, which deal with the contents of a bottle; a semi-micro ozonizer ; the handling of sodium; and the distillation of mercury. Each of the articles is intended to be the first of a series discussing severally the industrial production of chemicals, industrial apparatus, new reagents, and the teaching of chemistry. The inclusion of the last feature shows that thought and vision have gone to the planning of the Bulletin. For, manifestly, the promoters realize that in these days of the industrial importance of chemistry its teaching is of vital significance.

\section{Composite Wood}

THE term 'composite wood' is not perhaps very widely known, and the editor of the new journal, Composite Wood (1, No. 1; October 1953. From 15 Beeson Road, New Forest P.O., Dehra Dun, U.P., India ; price Rs. 2.8), has wisely set out on the title page his aims combined with a definition of the subject ". . . to promote the study and practice of the science and technology of composite wood (adhesives, plywood, laminated and other improved. woods, building boards, etc.), and allied subjects". The journal is a welcome addition to the very few devoted entirely to the technical aspect of composite wood matters, and should be of value to the plywood and allied industries, which are now established in all parts of the world. The editor, Dr. D. Narayanamurti, is in charge of the Composite Wood Branch of the Forest Research Institute, Dehra Dun, and he and his associates have contributed extensively to this first number. The inclusion of an article by Dr. F. Kollmann, of Germany, however, indicates the international aims of the journal. In addition to four technical papers, under "Notes and News" are information on meetings of specialist societies, details of forthcoming specifications, and references to manufacturers' publications on new adhesives. The abstracts deal fully with papers bearing on composite wood, and, in the present issue, two books are reviewed. It is understood that the journal will be published every two or three months.

\section{Maps of Africa South of the Sahara}

A LIST of "Maps of Africa South of the Sahara" has been compiled and published by the Scientific Council for Africa South of the Sahara (Publication No. 4; pp. ii +122 ; from the Council, Bukaru, Belgian Congo, 1953 ; 15 francs). The list attempts to show the position in 1953. Historical maps have been excluded and so also have maps on a scale smaller than $1: 1,000,000$. Atlases are listed, but their contents are not detailed in broad terms. Maps of special subjects are included, such as geology, climate, vegetation and population. The mapping of Africa is advancing at a great rate, and there are few areas that have no maps. Every entry gives the scale and source of publication.

\section{Molluscan Adaptation}

THE shell, mantle and organs in the mantle cavity of the characteristic Pinna carnea have been investigated in detail with special regard to their adaptation to the peculiar mode of life of this molluse by C. M. Yonge (Phil. Trans. Roy. Soc. Lond., B, No. 648; 1953). The shell, the shape of which recalls a partially opened fan, in the living animal is found with the pointed end embedded in the substratum with half its length, that is, considerably more than half its area, projecting freely upwards. This allows the inhalant current with its contained food particles to be drawn from clean water above the bottom and, conversely, the exhalant stream does not disturb the mud. However, standing upright and having free mantle lobes, the animal must be liable to a certain amount of silting, particularly when the surrounding mud is disturbed. We therefore find that it produces a strong exhalant current and that it has a special, powerfully ciliated waste canal well provided with mucous glands, which plays an important part in removing silt and the pseudofæces. Such a projecting shell, incapable of withdrawing, is liable to injury and the mantle is highly retractable and not attached to the part of the shell that is exposed, so that it can be withdrawn to escape injury. It can quickly carry out repairs, but it follows from its limited attach. ment that the shell in its projecting area is composed of the prismatic layer only. This layer is, as usual, constituted by a conchyolin network impregnated with calcite crystals arranged in prisms. There is a very much higher proportion of organic matter than in most molluses, so that the projecting part of the shell is flexible and hence less liable to breakage. The Pinnidae alone possess a pallial organ, a large unpaired tentacular structure, the function of which appears to be that of clearing away the broken pieces of shell.

\section{Chemical Basis of Resistance to Fungal Attack}

THE nature of the resistance of oats to Ophiobolus graminis has been investigated by E. M. Turner by testing the reactions of two varieties of the fungus to the sap (J.Exp. Bot., 4, $264 ; 1953)$. The two varieties of the take-all fungus, Ophiobolus graminis and $O$. graminis var. avenae, show a differential reaction to sap extracted from oats; the type variety, which is incapable of causing a lesting infection of osts in vivo, is inhibited by the sap in vitro, whereas var. avenae, pathogenic to oats, can grow in the sap. The inhibitory action of the sap is not due to a lack of food material required by the fungus, but to a specific substance or toxin. The method used for assaying toxicity is described. The inhibitor is produced in considerable quantity in the leaves and stems of oats and in smaller quantity in the roots. It appears to accumulate mainly during the period of active growth and to be less active, or present in smaller concentration, in adult plants. It can be detected in the seminal roots throughout their existence, although during the first three weeks of growth $O$. graminis can invade the cells of the cortex. It is present in greater quantity in the crown roots, which are never penetrated. A similar inhibitor of $O$. graminis can be extracted from Arrhenatherum elatius, but not from other grasses which, both in the field and in pot experiments, appear to be equally resistant. 